\title{
DETOUR ENERGY OF COMPLEMENT OF SUBGROUP GRAPH OF DIHEDRAL GROUP
}

\author{
Abdussakir \\ Department of Mathematics \\ UIN Maulana Malik Ibrahim Malang \\ sakir@mat.uin-malang.ac.id
}

\begin{abstract}
Study on the energy of a graph becomes a topic of great interest. One is the detour energy which is the sum of the absolute values of all eigenvalue of the detour matrix of a graph. Graphs obtained from a group also became a study that attracted the attention of many researchers. This article discusses the subgroup graph for several normal subgroups of dihedral groups. The discussion focused on the detour energy of complement of subgroup graph of dihedral group.
\end{abstract}

Key Word: Detour energy, complement of subgroup graph, dihedral group, normal subgroup

\begin{abstract}
Abstrak Penelitian terkait energi suatu graf menjadi topik yang banyak diminati. Salah satunya adalah energi detour yang merupakan jumlah dari nilai mutlak semua nilai eigen matriks detour suatu graf. Graf yang diperoleh dari suatu grup juga menjadi kajian yang menarik perhatian banyak peneliti. Artikel ini membahas graf subgrup untuk beberapa subgroup normal dari grup dihedral. Pembahasan difokuskan energi detour komplemen graf subgroup dari grup dihedral.
\end{abstract}

Kata Kunci: Energi detour, komplemen graf subgrup, grup dihedral, subgroup normal 


\section{Pendahuluan}

Graf dalam artikel ini adalah berhingga, tidak memuat gelung, dan tidak memuat sisi rangkap. Himpunan titik pada graf $G$ ditulis $V(G)$ sedangkan himpunan sisi di $G$ ditulis $E(G)$. Kardinalitas $V(G)$ disebut order $G$ dan dinotasikan dengan $p$. Kardinalitas $E(G)$ disebut ukuran $G$ dan dinotasikan dengan $q$ (Abdussakir, Azizah, \& Nofandika, 2009). Dua titik $u$ dan $v$ di $G$ dikatakan terhubung jika terdapat lintasan $u-v$ di $G$. Graf $G$ dikatakan terhubung jika untuk setiap dua titik berbeda di $G$ adalah terhubung (Chartrand, Lesniak, \& Zhang, 2016).

Misalkan $G$ adalah graf terhubung dengan order $p$. Matriks detour dari $G$ yang dinotasikan dengan $D D(G)$ adalah matriks berukuran $(p \times p)$ sedemikian hingga unsur pada baris ke- $i$ dan kolom ke- $j$ adalah panjang lintasan terpanjang dari $v_{i}$ ke $v_{j}$ di $G$ (Ayyaswamy \& Balachandran, 2010). Misalkan $\lambda_{1}, \lambda_{2}, \ldots, \lambda_{n}$ adalah semua nilai eigen dari matriks $D D(G)$, maka energi detour didefinisikan sebagai $E_{D D}(G)=\sum_{i=1}^{n}\left|\lambda_{i}\right|$ (Ayyaswamy \& Balachandran, 2010).

Beberapa penelitian mengenai energi suatu graf sudah dilakukan, misalnya energi keterkaitan (Xu \& Xu, 2016), energi Laplace (Shabaf \& Fayazi, 2014), energi Laplace warna (Bhat \& D'Souza, 2015), energi signless Laplace warna (Bhat \& D'Souza, 2017), (Das, Sorgun, \& Xu, 2014), dan energi jarak (Ramane et al., 2008). Ayyaswamy dan Balachandran (2010) meneliti energi detour pada beberapa graf dan hasil operasinya. Dengan demikian penelitian mengenai energi detour masih perlu dilakukan.

Teori graf juga membahas graf yang dibangun dari grup, misalnya graf komuting, graf non komuting, graf koset, graf perpangkatan, graf konjugasi, graf invers, dan graf subgrup. Anderson dkk (2012) mengenalkan konsep graf subgrup. Misalkan $G$ grup dan $H$ subgrup $G$, maka $\Gamma H(G)$ adalah graf berarah (digraph) dengan titik semua unsur di $G$ dan titik $x$ terhubung langsung ke $y$ (atau ada busur dari $x$ ke $y$ ) jika dan hanya jika $x \neq y$ dan $x y \in H$. Jika $x y \in H$ dan $y x \in H$ untuk suatu $x, y \in G$ dengan $x \neq y$ maka $x$ dan $y$ dihubungkan langsung oleh suatu sisi tak berarah. Dengan demikian, akan diperoleh graf $\Gamma H(G)$ yang tidak memuat gelung dan sisi rangkap. Graf $\Gamma н(G)$ ini disebut graf subgrup dari $G$. Kakeri dan Erfanian (2015) menjelaskan bahwa graf subgrup $Г н(G)$ jelas eksistensinya ketika $H$ adalah subgrup normal dari $G$.

Penelitian mengenai graf subgrup baru ada 3 yaitu penelitian Anderson dkk (2012), Kakeri \& Erfanian (2015), dan Abdussakir dkk (2017). Anderson dkk (2012) meneliti struktur komponen-kompenen yang terhubung pada graf subgrup $Г н(G)$. Kakeri \& Erfanian (2015) meneliti sifat-sifat komplemen graf subgrup $\overline{\Gamma_{H}(G)}$. Sifat-sifat yang diteliti meliputi diameter, girth, himpunan bebas dan himpunan dominasi, serta keteraturannya. Abdussakir dkk (2017) meneliti spektrum graf subgrup dan komplemen graf subgrup dari grup dihedral.

Berdasarkan uraian tersebut, penelitian mengenai energi detour graf subgrup masih perlu untuk dilakukan. Pada artikel ini dijelaskan energi detour komplemen graf subgrup dari grup dihedral. 


\section{Kajian Teori}

Graf $G$ adalah pasangan $(V(G), E(G))$ dengan $V(G)$ adalah himpunan tak kosong dan berhingga dari objek-objek yang disebut titik, dan $E(G)$ adalah himpunan (mungkin kosong) pasangan takberurutan dari titik-titik berbeda di $V(G)$ yang disebut sisi (Abdussakir et al., 2009). Sisi $e=(u, v)$ dikatakan menghubungkan titik $u$ dan $v$. Jika $e=$ $(u, v)$ adalah sisi di graf $G$, maka $u$ dan $v$ disebut terhubung langsung. Untuk selanjutnya, sisi $e=(u, v)$ akan ditulis $e=u v$ (Bondy \& Murty, 2008).

Derajat titik $v$ pada graf $G$ adalah banyak sisi di $G$ yang terkait langsung dengan $v$ (Chartrand et al., 2016). Titik yang berderajat 0 disebut titik terasing atau titik terisolasi. Titik yang berderajat 1 disebut titik ujung atau titik akhir. Titik yang berderajat genap disebut titik genap dan titik yang berderajat ganjil disebut titik ganjil. Derajat maksimum titik di $G$ dilambangkan dengan $\Delta(G)$ dan derajat minimum titik di $G$ dilambangkan dengan $\delta(G)$ (Bondy \& Murty, 1976).

Graf $G$ dikatakan komplit jika setiap dua titik yang berbeda saling terhubung langsung. Graf komplit dengan order $n$ ditulis $K_{n}$. Graf $G$ dikatakan bipartisi jika himpunan titik pada $G$ dapat dipartisi menjadi dua himpunan tak kosong $V_{1}$ dan $V_{2}$ sehingga masing-masing sisi pada graf $G$ tersebut menghubungkan satu titik di $V_{1}$ dengan satu titik di $V_{2}$. Graf $G$ disebut bipartisi komplit jika $G$ adalah graf bipartisi dan masingmasing titik pada suatu partisi terhubung langsung dengan semua titik pada partisi yang lain. Graf bipartisi komplit dengan $m$ titik pada salah satu partisi dan $n$ titik pada partisi yang lain ditulis $K_{m, n}$ (Bondy \& Murty, 1976:4-5).

Komplemen graf $G$ yang dinotasikan dengan $\bar{G}$ adalah graf dengan $V(\bar{G})=V(G)$ dan dua titik akan terhubung langsung di $\bar{G}$ jika dan hanya jika dua titik tersebut tidak terhubung langsung di $G$ (Chartrand et al., 2016). Dengan kata lain, $x y \in E(\bar{G})$ jika dan hanya jika $x y \notin E(G)$. Jika $G$ graf berorder $p$, maka diperoleh $q(G)+q(\bar{G})=q\left(K_{p}\right)$ (Abdussakir et al., 2009).

Misalkan $u$ dan $v$ adalah titik di $G$. Jalan $u-v$ pada graf $G$ adalah barisan berhingga yang berselang-seling $W: u=v_{0}, e_{1}, v_{1}, e_{2}, v_{2}, \ldots, v_{n-1}, e_{n}, v_{n}=v$ antara titik dan sisi, yang dimulai dari titik dan diakhiri dengan titik, dengan $e_{i}=v_{i-1} v_{i}(i=1,2,3, \ldots, n)$ adalah sisi di G. $v_{0}$ disebut titik awal, $v_{n}$ disebut titik akhir, titik $v_{1}, v_{2}, \ldots, v_{n-1}$ disebut titik internal, dan $n$ menyatakan panjang dari $W$. Jika $v_{0} \neq v_{n}$, maka $W$ disebut jalan terbuka. Jika $v_{0}=v_{n}$, maka $W$ disebut jalan tertutup (Chartrand et al., 2016:37).

Jalan $W$ yang semua sisinya berbeda disebut trail. Jalan terbuka yang semua titiknya berbeda disebut lintasan. Jalan tertutup yang semua titik internalnya berbeda disebut sikel (Bondy \& Murty, 1976:53). Lintasan yang memuat semua titik di $G$ disebut lintasan Hamilton. Sikel yang memuat semua titik di $G$ disebut sikel Hamilton.

Graf yang memuat sikel Hamilton disebut graf Hamilton (Chartrand et al., 2016:128). Jika graf $G$ dengan order $p \geq 3$ memiliki $\delta(G) \geq p / 2$ maka $G$ adalah graf Hamilton (Bondy \& Murty, 1976:54).

Misalkan $u$ dan $v$ titik berbeda di graf $G$. Titik $u$ dan $v$ dikatakan terhubung jika terdapat lintasan $u-v$ di $G$. Graf $G$ dikatakan terhubung jika untuk setiap titik $u$ dan $v$ yang berbeda di $G$ terhubung. Dengan kata lain, suatu graf $G$ dikatakan terhubung jika untuk 
setiap titik $u$ dan $v$ di $G$ terdapat lintasan $u-v$ di $G$. Graf yang tidak terhubung disebut graf takterhubung (Chartrand et al., 2016). Jika graf $G$ tak terhubung maka $\bar{G}$ terhubung (Bondy \& Murty, 2008:11).

Misalkan $G$ grup dan $H$ himpunan bagian di $G$. Jika $H$ dengan operasi biner yang sama dengan di $G$ membentuk grup, maka $H$ disebut subgrup dari $G$ dan dinotasikan dengan $H \leq G$ (Dummit \& Foote, 1991:26). Jika $g \in \mathrm{G}$ maka subgrup yang dibangkitkan oleh g ditulis $\langle g\rangle$, yaitu $\langle g\rangle=\left\{g^{n} \mid n \in \mathbb{Z}\right\}$. Secara umum, jika $g_{1}, g_{2}, \ldots, g_{k} \in G$ maka subgrup yang dibangkitkan oleh $g_{1}, g_{2}, \ldots, g_{k}$ ditulis $\left\langle g_{1}, g_{2}, \ldots, g_{k}>\right.$. Jika $H \leq G$ dan berlaku $g h g^{-1} \in$ $H$ untuk semua $h \in H$ dan $g \in G$, maka $H$ disebut subgrup normal dari $G$ dan dinotasikan dengan $H \unlhd G$. Dengan kata lain $H$ subgrup normal di $G$ jika dan hanya jika $g H^{-1}=H$ atau $g H=H g$, untuk semua $g \in G$ (Gilbert \& Nicholson, 2004).

Grup dihedral adalah grup yang memuat simetri-simetri pada segi- $n$ beraturan dan dinotasikan dengan $D_{2 n}$, untuk setiap $n$ bilangan bulat positif dan $n \geq 3$ (Dummit \& Foote, 1991). Secara sederhana $D_{2 n}=\left\{1, r, r^{2}, \ldots, r^{n-1}, s, s r, s r^{2}, \ldots, s r^{n-1}\right\}$ sehingga $D_{2 n}$ berorder $2 n$. Untuk $n$ ganjil, maka subgrup normal dari $D_{2 n}$ adalah $\langle r\rangle,\langle r d\rangle$ dengan syarat $d$ membagi $n$, dan $D_{2 n}$ sendiri. Untuk $n$ genap, maka subgrup normal dari $D_{2 n}$ adalah $<r>$, $\left\langle r^{d}>\right.$ dengan syarat $d$ membagi $n,\left\langle r^{2}, s\right\rangle,\left\langle r^{2}, r s>\right.$, dan $D_{2 n}$ sendiri. Pada artikel ini hanya dibahas graf subgrup $D_{2 n}$ untuk subgrup $\langle r\rangle,\left\langle r^{2}\right\rangle,\left\langle r^{2}, s\right\rangle$, dan $\left\langle r^{2}, r s\right\rangle$.

\section{Hasil}

Sebelum membahas secara umum, berikut diberikan contoh pada grup dihedral $D_{6}$. Grup dihedral $D_{6}=\left\{1, r, r^{2}, s, s r, s r^{2}\right\}$ dengan operasi fungsi komposisi dapat dinyatakan dalam tabel Cayley berikut

Tabel 1 Tabel Cayley Grup Dihedral $D_{6}$

\begin{tabular}{|c|c|c|c|c|c|c|}
\hline$\circ$ & 1 & $r$ & $r^{2}$ & $s$ & $s r$ & $s r^{2}$ \\
\hline 1 & 1 & $r$ & $r^{2}$ & $s$ & $s r$ & $s r^{2}$ \\
\hline$r$ & $r$ & $r^{2}$ & 1 & $s r^{2}$ & $s$ & $s r$ \\
\hline$r^{2}$ & $r^{2}$ & 1 & $r$ & $s r$ & $s r^{2}$ & $s$ \\
\hline$s$ & $s$ & $s r$ & $s r^{2}$ & 1 & $r$ & $r^{2}$ \\
\hline$s r$ & $s r$ & $s r^{2}$ & $s$ & $r^{2}$ & 1 & $r$ \\
\hline$s r^{2}$ & $s r^{2}$ & $s$ & $s r$ & $r$ & $r^{2}$ & 1 \\
\hline
\end{tabular}

Dengan mengambil subgrup normal $\langle r\rangle=\left\{1, r, r^{2}\right\}$, maka sesuai definisi graf subgrup diperoleh graf subgrup $\Gamma_{\langle r\rangle}\left(D_{6}\right)$ sebagai berikut
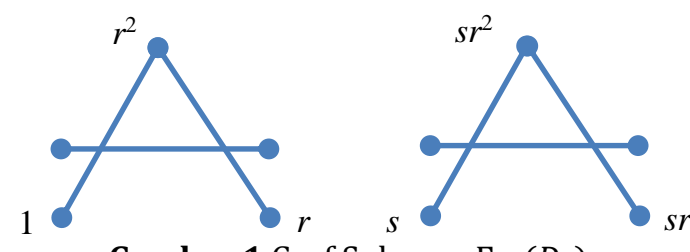

Gambar 1 Graf Subgrup $\Gamma_{\langle r\rangle}\left(D_{6}\right)$ 
Graf subgrup $\Gamma_{\langle r\rangle}\left(D_{6}\right)$ adalah graf takterhubung sehingga $\overline{\Gamma_{\langle r\rangle}\left(D_{6}\right)}$ adalah graf terhubung. Komplemen dari $\Gamma_{\langle r\rangle}\left(D_{6}\right)$ dapat digambarkan sebagai berikut

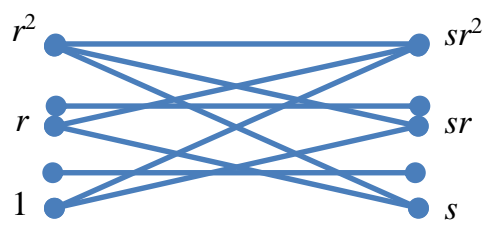

Gambar 2 Graf Subgrup $\Gamma_{\langle r\rangle}\left(D_{6}\right)$

Graf $\overline{\Gamma_{\langle r\rangle}\left(D_{6}\right)}$ adalah graf bipartisi komplit $K_{3,3}$. Akibatnya, panjang lintasan terpanjang antara dua titik berbeda di $\overline{\Gamma_{\langle r\rangle}\left(D_{6}\right)}$ adalah 4 jika dalam satu partisi dan 5 jika dalam partisi berbeda. Maka diperoleh matriks detour berikut

$$
D D\left(\overline{\Gamma_{\langle r\rangle}\left(D_{6}\right)}\right)=\left[\begin{array}{llllll}
0 & 4 & 4 & 5 & 5 & 5 \\
4 & 0 & 4 & 5 & 5 & 5 \\
4 & 4 & 0 & 5 & 5 & 5 \\
5 & 5 & 5 & 0 & 4 & 4 \\
5 & 5 & 5 & 4 & 0 & 4 \\
5 & 5 & 5 & 4 & 4 & 0
\end{array}\right]
$$

Menggunakan persamaan $\operatorname{det}\left(D D\left(\overline{\Gamma_{\langle r\rangle}\left(D_{6}\right)}\right)-\lambda I\right)=0$ maka diperoleh persamaan karakteristik $p(\lambda)=(\lambda-23)(\lambda+4)^{4}(\lambda+7)$. Jadi, semua nilai eigen dari $D D\left(\overline{\Gamma_{\langle r\rangle}\left(D_{6}\right)}\right)$ adalah $23,-4,-4,-4,-4,-7$. Maka $E_{D D}\left(D_{6}\right)=|23|+|-4|+|-4|+|-4|+|-4|+|-7|=$ 46. Dengan cara lain, nilai eigen dari $D D\left(\overline{\Gamma_{\langle r\rangle}\left(D_{6}\right)}\right)$ adalah $\lambda_{1}=23, \lambda_{2}=-4$, dan $\lambda_{3}=-7$ dengan multiplisitas $m\left(\lambda_{1}\right)=1, m\left(\lambda_{2}\right)=4$, dan $m\left(\lambda_{3}\right)=1$. Maka energi detour dapat dihitung dengan $E_{D D}\left(\overline{\Gamma_{\langle r\rangle}\left(D_{6}\right)}\right)=1 \times|23|+4 \times|-4|+1 \times|-7|=23+16+7=46$.

Teorema-teorema berikut merupakan hasil utama penelitian ini.

\section{Teorema 1}

Energi detour komplemen graf subgrup $\overline{\Gamma_{\langle r\rangle}\left(D_{2 n}\right)}$ dengan $n \geq 3$ adalah

$$
E_{D D}\left(\overline{\Gamma_{\langle r\rangle}\left(D_{2 n}\right)}\right)=8 n^{2}-10 n+4
$$

\section{Bukti}

Komplemen graf subgroup $\overline{\Gamma_{\langle r\rangle}\left(D_{2 n}\right)}$ adalah graf bipartisi komplit dengan $n$ titik pada masing-masing partisi, yaitu $V_{1}=\left\{1, r, r^{2}, \ldots, r^{n-1}\right\}$ dan $V_{2}=\left\{s, s r, s r^{2}, \ldots, s r^{n-1}\right\}$. Maka lintasan terpanjang antara dua titik berbeda mempunyai panjang $2 n-2$ jika terletak dalam satu partisi dan $2 n-1$ jika terletak dalam partisi berbeda. Jadi, $D D\left(\overline{\Gamma_{\langle r\rangle}\left(D_{2 n}\right)}\right)=\left[\begin{array}{ll}A & B \\ B & A\end{array}\right]$ dengan $A=(2 \mathrm{n}-2)(J-I)$ dan $B=(2 \mathrm{n}-1)(), J$ matriks berordo $n \times n$ yang semua entrinya satu dan $I$ matriks identitas ordo $n \times n$. Polinomial karakteristik $D D\left(\overline{\Gamma_{\langle r\rangle}\left(D_{2 n}\right)}\right)$ diperoleh dari $\operatorname{det}\left(D D\left(\overline{\Gamma_{\langle r\rangle}\left(D_{2 n}\right)}\right)-\lambda I\right)$. Menggunakan eliminasi Gauss pada matriks $D D\left(\overline{\Gamma_{\langle r\rangle}\left(D_{2 n}\right)}\right)-\lambda I$ akan diperoleh polinomial karakteristik

$$
p(\lambda)=\left(\lambda-\left(4 n^{2}-5 n+2\right)\right)(\lambda+(2 n-2))^{2(n-1)}(\lambda+(3 n-2)) .
$$


Dengan $p(\lambda)=0$ maka diperoleh nilai eigen $\lambda_{1}=\left(4 n^{2}-5 n+2\right), \lambda_{2}=-(2 n-2)$, dan $\lambda_{3}=-(3 n-2)$ dengan multiplisitas $m\left(\lambda_{1}\right)=1, m\left(\lambda_{2}\right)=2 n-2$, dan $m\left(\lambda_{3}\right)=1$. Jadi, energi detour komplemen graf subgrup $\overline{\Gamma_{\langle r\rangle}\left(D_{2 n}\right)}$ adalah

$$
\begin{aligned}
E_{D D}\left(\overline{\Gamma_{\langle r\rangle}\left(D_{2 n}\right)}\right) & =m\left(\lambda_{1}\right)\left|\lambda_{1}\right|+m\left(\lambda_{2}\right)\left|\lambda_{2}\right|+m\left(\lambda_{3}\right)\left|\lambda_{3}\right| \\
& =\left|4 n^{2}-5 n+2\right|+(2 n-2)|-(2 n-2)|+|-(3 n-2)| \\
& =4 n^{2}-5 n+2+(2 n-2)^{2}+(3 n-2) \\
& =8 n^{2}-10 n+4 .
\end{aligned}
$$

\section{Teorema 2}

Energi detour komplemen graf subgroup $\overline{\Gamma_{\left\langle r^{2}\right\rangle}\left(D_{2 n}\right)}$ untuk $n$ genap dan $n \geq 4$ adalah

$$
E_{D D}\left(\overline{\Gamma_{\langle r\rangle}\left(D_{6}\right)}\right)=2(2 n-1)^{2} \text {. }
$$

\section{Bukti}

Lintasan terpanjang antara dua titik berbeda pada $\overline{\Gamma_{\left\langle r^{2}\right\rangle}\left(D_{2 n}\right)}$ adalah $2 n-1$. Maka matriks detour komplemen graf subgroup $\overline{\Gamma_{\left\langle r^{2}\right\rangle}\left(D_{2 n}\right)}$ adalah

$$
D D\left(\overline{\Gamma_{\left\langle r^{2}\right\rangle}\left(D_{2 n}\right)}\right)=\left[D D_{i j}\right]
$$

dengan $D D_{i j}=2 n-1$ untuk $i \neq j$ dan $D D_{i j}=0$ untuk lainnya. Polinomial karakteristik $D D\left(\overline{\Gamma_{\left\langle r^{2}\right\rangle}\left(D_{2 n}\right)}\right)$ diperoleh dari $\operatorname{det}\left(D D\left(\overline{\Gamma_{\left\langle r^{2}\right\rangle}\left(D_{2 n}\right)}\right)-\lambda I\right)$. Menggunakan eliminasi Gauss pada matriks $D D\left(\overline{\Gamma_{\left\langle r^{2}\right\rangle}\left(D_{2 n}\right)}\right)-\lambda I$ akan diperoleh persamaan karakteristik

$$
p(\lambda)=\left(\lambda-(2 n-1)^{2}\right)(\lambda+(2 n-1))^{2 n-1}=0 .
$$

Dengan demikian diperoleh nilai eigen $\lambda_{1}=(2 n-1)^{2}$ dan $\lambda_{2}=-(2 n-1)$ dengan multiplisitas $m\left(\lambda_{1}\right)=1$ dan $m\left(\lambda_{2}\right)=2 n-1$. Jadi, energi detour komplemen graf subgrup $\overline{\Gamma_{\langle r\rangle}\left(D_{2 n}\right)}$ adalah

$$
\begin{aligned}
E_{D D}\left(\overline{\Gamma_{\langle r\rangle}\left(D_{2 n}\right)}\right) & =m\left(\lambda_{1}\right)\left|\lambda_{1}\right|+m\left(\lambda_{2}\right)\left|\lambda_{2}\right| \\
& =\left|(2 n-1)^{2}\right|+(2 n-1)|-(2 n-1)| \\
& =(2 n-1)^{2}+(2 n-1)^{2} \\
& =2(2 n-1)^{2} .
\end{aligned}
$$

\section{Teorema 3}

Energi detour komplemen graf subgroup $\overline{\Gamma_{\left\langle r^{2}, s\right\rangle}\left(D_{2 n}\right)}$ untuk $n$ genap dan $n \geq 4$ adalah $E_{D D}\left(\overline{\Gamma_{\left\langle r^{2}, s\right\rangle}\left(D_{2 n}\right)}\right)=8 n^{2}-10 n+4$.

\section{Bukti:}

Matriks detour komplemen graf subgroup $\overline{\Gamma_{\left\langle r^{2}, s\right\rangle}\left(D_{2 n}\right)}$ untuk $n$ genap dan $n \geq 4$ adalah

$$
D D\left(\overline{\Gamma_{\left\langle r^{2}, s\right\rangle}\left(D_{2 n}\right)}\right)=\left[\begin{array}{ccccccccc}
0 & 2 n-1 & 2 n-2 & \ldots & 2 n-1 & 2 n-2 & 2 n-1 & \ldots & 2 n-1 \\
2 n-1 & 0 & 2 n-1 & \ldots & 2 n-2 & 2 n-1 & 2 n-2 & \ldots & 2 n-2 \\
2 n-2 & 2 n-1 & 0 & \ldots & 2 n-1 & 2 n-2 & 2 n-1 & \ldots & 2 n-1 \\
\vdots & \vdots & \vdots & & \vdots & \vdots & \vdots & & \vdots \\
2 n-1 & 2 n-2 & 2 n-1 & \ldots & 0 & 2 n-1 & 2 n-2 & \ldots & 2 n-2 \\
2 n-2 & 2 n-1 & 2 n-2 & \ldots & 2 n-1 & 0 & 2 n-1 & \ldots & 2 n-1 \\
2 n-1 & 2 n-2 & 2 n-1 & \ldots & 2 n-2 & 2 n-1 & 0 & \ldots & 2 n-2 \\
\vdots & \vdots & \vdots & & \vdots & \vdots & \vdots & & \vdots \\
2 n-1 & 2 n-2 & 2 n-1 & \ldots & 2 n-2 & 2 n-1 & 2 n-2 & \ldots & 0
\end{array}\right]
$$

Polinomial karakteristik $D D\left(\overline{\Gamma_{\left\langle r^{2}, s\right\rangle}\left(D_{2 n}\right)}\right)$ diperoleh dari $\operatorname{det}\left(D D\left(\overline{\Gamma_{\left\langle r^{2}, s\right\rangle}\left(D_{2 n}\right)}\right)-\lambda I\right)$. Dengan eliminasi Gauss pada $D D\left(\overline{\Gamma_{\left\langle r^{2}, s\right\rangle}\left(D_{2 n}\right)}\right)-\lambda I$ diperoleh matriks segitiga atas. 
Maka $\operatorname{det}\left(D D\left(\overline{\Gamma_{\left\langle r^{2}, s\right\rangle}\left(D_{2 n}\right)}\right)-\lambda I\right)$ tidak lain adalah perkalian semua unsur diagonal utama matriks segitiga atas tersebut. Maka polinomial karakteristik dari $D D\left(\overline{\Gamma_{\left\langle r^{2}, S\right\rangle}\left(D_{2 n}\right)}\right)$ adalah

$$
p(\lambda)=\left(\lambda-\left(4 n^{2}-5 n+2\right)\right)(\lambda+(2 n-2))^{2(n-1)}(\lambda+(3 n-2)) .
$$

Dengan $p(\lambda)=0$, akan diperoleh nilai eigen $\lambda_{1}=\left(4 n^{2}-5 n+2\right), \lambda_{2}=-(2 n-2)$, dan $\lambda_{3}=-(3 n-2)$ dengan multiplisitas $m\left(\lambda_{1}\right)=1, m\left(\lambda_{2}\right)=2 n-2$, dan $m\left(\lambda_{3}\right)=1$. Jadi, energi detour komplemen graf subgrup $\overline{\Gamma_{\langle r\rangle}\left(D_{2 n}\right)}$ adalah

$$
\begin{aligned}
E_{D D}\left(\overline{\Gamma_{\langle r\rangle}\left(D_{2 n}\right)}\right) & =m\left(\lambda_{1}\right)\left|\lambda_{1}\right|+m\left(\lambda_{2}\right)\left|\lambda_{2}\right|+m\left(\lambda_{3}\right)\left|\lambda_{3}\right| \\
& =\left|4 n^{2}-5 n+2\right|+(2 n-2)|-(2 n-2)|+|-(3 n-2)| \\
& =4 n^{2}-5 n+2+(2 n-2)^{2}+(3 n-2) \\
& =8 n^{2}-10 n+4 .
\end{aligned}
$$

\section{Teorema 4}

Energi detour komplemen graf subgroup $\overline{\Gamma_{\left\langle r^{2}, r s\right\rangle}\left(D_{2 n}\right)}$ untuk $n$ genap dan $n \geq 4$ adalah $E_{D D}\left(\overline{\Gamma_{\left\langle r^{2}, r s\right\rangle}\left(D_{2 n}\right)}\right)=8 n^{2}-10 n+4$.

\section{Bukti:}

Matriks detour komplemen graf subgroup $\overline{\Gamma_{\left\langle r^{2}, s\right\rangle}\left(D_{2 n}\right)}$ untuk $n$ genap dan $n \geq 4$ adalah

$$
D D\left(\overline{\Gamma_{\left\langle r^{2}, r s\right\rangle}\left(D_{2 n}\right)}\right)=\left[\begin{array}{ccccccccc}
0 & 2 n-1 & 2 n-2 & \ldots & 2 n-1 & 2 n-1 & 2 n-2 & \ldots & 2 n-2 \\
2 n-1 & 0 & 2 n-1 & \ldots & 2 n-2 & 2 n-2 & 2 n-1 & \ldots & 2 n-1 \\
2 n-2 & 2 n-1 & 0 & \ldots & 2 n-1 & 2 n-1 & 2 n-2 & \ldots & 2 n-2 \\
\vdots & \vdots & \vdots & & \vdots & \vdots & \vdots & & \vdots \\
2 n-1 & 2 n-2 & 2 n-1 & \ldots & 0 & 2 n-2 & 2 n-1 & \ldots & 2 n-1 \\
2 n-1 & 2 n-2 & 2 n-1 & \ldots & 2 n-2 & 0 & 2 n-1 & \ldots & 2 n-1 \\
2 n-2 & 2 n-1 & 2 n-2 & \ldots & 2 n-1 & 2 n-1 & 0 & \ldots & 2 n-2 \\
\vdots & \vdots & \vdots & & \vdots & \vdots & \vdots & & \vdots \\
2 n-2 & 2 n-1 & 2 n-2 & \ldots & 2 n-1 & 2 n-1 & 2 n-2 & \ldots & 0
\end{array}\right]
$$

Polinomial karakteristik $D D\left(\overline{\Gamma_{\left\langle r^{2}, r s\right\rangle}\left(D_{2 n}\right)}\right)$ diperoleh dari $\operatorname{det}\left(D D\left(\overline{\Gamma_{\left\langle r^{2}, r s\right\rangle}\left(D_{2 n}\right)}\right)-\right.$ $\lambda I)$. Dengan eliminasi Gauss pada $D D\left(\overline{\Gamma_{\left\langle r^{2}, r s\right\rangle}\left(D_{2 n}\right)}\right)-\lambda I$ akan diperoleh persamaan karakteristik dari $D D\left(\overline{\Gamma_{\left\langle r^{2}, r s\right\rangle}\left(D_{2 n}\right)}\right)$ adalah

$$
p(\lambda)=\left(\lambda-\left(4 n^{2}-5 n+2\right)\right)(\lambda+(2 n-2))^{2(n-1)}(\lambda+(3 n-2))=0 .
$$

Maka diperoleh nilai eigen $\lambda_{1}=\left(4 n^{2}-5 n+2\right), \lambda_{2}=-(2 n-2)$, dan $\lambda_{3}=-(3 n-2)$ dengan multiplisitas $m\left(\lambda_{1}\right)=1, m\left(\lambda_{2}\right)=2 n-2$, dan $m\left(\lambda_{3}\right)=1$. Jadi, energi detour komplemen graf subgrup $\overline{\Gamma_{\left\langle r^{2}, r s\right\rangle}\left(D_{2 n}\right)}$ adalah

$$
\begin{aligned}
E_{D D}\left(\overline{\Gamma_{\left\langle r^{2}, r s\right\rangle}\left(D_{2 n}\right)}\right) & =m\left(\lambda_{1}\right)\left|\lambda_{1}\right|+m\left(\lambda_{2}\right)\left|\lambda_{2}\right|+m\left(\lambda_{3}\right)\left|\lambda_{3}\right| \\
= & \left|4 n^{2}-5 n+2\right|+(2 n-2)|-(2 n-2)|+|-(3 n-2)| \\
= & 4 n^{2}-5 n+2+(2 n-2)^{2}+(3 n-2) \\
= & 8 n^{2}-10 n+4 .
\end{aligned}
$$

Dari hasil tersebut dapat diketahui bahwa energi detour komplemen graf subgrup $\overline{\Gamma_{\langle r\rangle}\left(D_{2 n}\right)}, \overline{\Gamma_{\left\langle r^{2}, s\right\rangle}\left(D_{2 n}\right)}$, dan $\overline{\Gamma_{\left\langle r^{2}, r s\right\rangle}\left(D_{2 n}\right)}$ adalah sama sehingga ketiga graf tersebut dapat dinamakan equienergetics. Hal ini terjadi karena $\overline{\Gamma_{\langle r\rangle}\left(D_{2 n}\right)}, \overline{\Gamma_{\left\langle r^{2}, s\right\rangle}\left(D_{2 n}\right)}$, dan $\overline{\Gamma_{\left\langle r^{2}, r s\right\rangle}\left(D_{2 n}\right)}$ adalah graf bipartisi komplit dengan $n$ unsur pada masing-masing partisi. 


\section{Kesimpulan}

Artikel ini hanya membahas energi detour pada komplemen graf subgrup dari grup dihedral untuk subgrup normal $\langle r\rangle$ serta $\left\langle r^{2}\right\rangle,\left\langle r^{2}, s\right\rangle$, dan $\left\langle r^{2}, r s\right\rangle$ untuk $n$ genap. Penelitian lebih lanjut mengenai energi detour masih dapat dilakukan pada subgroup normal yang lain di grup dihedral $D_{2 n}$ atau di grup yang lain seperti grup simetri $S_{n}$, grup matriks $M_{n}(\mathbb{Z})$, atau grup hasil bagi $\mathbb{Z} / n \mathbb{Z}$.

\section{Daftar Pustaka}

[1] Abdussakir, Akhadiyah, D. A., Layali, A., \& Putra, A. T. (2017). Spektrum graf subgrup dan komplemen graf subgrup dari grup dihedral. Laporan Penelitian. Malang: Fakultas Sains dan Teknologi.

[2] Abdussakir, Azizah, N. N., \& Nofandika, F. F. (2009). Teori graf: Topik dasar untuk tugas akhir/skripsi. Malang: UIN Malang Press.

[3] Anderson, D. F., Fasteen, J., \& Lagrange, J. D. (2012). The subgroup graph of a group. Arab Journal of Mathematics, 1, 17-27.

[4] Ayyaswamy, S. K., \& Balachandran, S. (2010). On detour spectra of some graphs. International Journal of Mathematical, Computational, Physical, Electrical and Computer Engineering, 4(7), 1038-1040.

[5] Bhat, P. G., \& D'Souza, S. (2015). Color Laplacian energy of a graph. Proceedings of the Jangjeon Mathematical Society, 18(3), 321-330.

[6] Bhat, P. G., \& D'Souza, S. (2017). Color signless Laplacian energy of graphs. AKCE International Journal of Graphs and Combinatorics, 14(2), 142-148.

[7] Bondy, J. A., \& Murty, U. S. R. (1976). Graph theory with applications. North-Holland. New York: Elsevier Science Publishing Co., Inc.

[8] Bondy, J. A., \& Murty, U. S. R. (2008). Graph theory. New York: Springer.

[9] Chartrand, G., Lesniak, L., \& Zhang, P. (2016). Graphs and Digraphs (6th ed.). Florida: CRC Press.

[10] Das, K. C., Sorgun, S., \& Xu, K. (2014). On Randic energy of graphs. MATCH Commun. Math. Comput. Chem, 72, 227-238.

[11] Dummit, D. S., \& Foote, R. M. (1991). Abstract Algebra. Englewood Cliffs, NJ: Prentice Hall.

[12] Gilbert, W. J., \& Nicholson, W. K. (2004). Modern algebra with applications. John Wiley \& Sons, Inc. (2nd ed.). New Jersey: John Wiley \& Sons, Inc.

[13] Kakeri, F., \& Erfanian, A. (2015). The complement of subgroup graph of a group. Journal of Prime Research in Mathematics, 11, 55-60.

[14] Ramane, H. S., Revankar, D. S., Gutman, I., Rao, S. B., Acharya, B. D., \& Walikar, H. B. (2008). Bounds for the distance energy of a graph. Kragujevac Journal of Mathematics, 31, 59-68.

[15] Shabaf, S. R., \& Fayazi, F. (2014). Laplacian Energy of a Fuzzy Graph. Iranian Journal of Mathematical Chemstry, 5(1), 1-10.

[16] Xu, L., \& Xu, X. (2016). On incidence energy of tree. Ars Combinatoria, 126, 93-107. 